\title{
Avaliação das características físico-químicas, fungos e ocratoxina A em uvas Merlot parcialmente desidratadas em ambiente naturalmente ventilado
}

\author{
Tássia Henrique Nievierowski ${ }^{1}$, Flávio Fonseca Verasi ${ }^{1}$, Rafaela Diogo Silveirai ${ }^{1}$, \\ Fernanda Cortez Lopesi ${ }^{2}$, Juliane Elisa Welkei ${ }^{1}$
}

\begin{abstract}
Resumo
A desidratação parcial das uvas tem sido usada para produzir vinhos especiais, alguns dos quais são certificados como "Denominação de Origem Controlada". Este procedimento é realizado pré ou pós- colheita em várias regiões do mundo. A desidratação em câmaras ou salas pode ser realizada independentemente das condições climáticas, além dos benefícios de proteger as uvas dos danos causados por pássaros/insetos e poluição ambiental. O objetivo deste estudo foi avaliar as características físico-químicas, incidência de fungos e ocratoxina A em uvas Merlot submetidas à desidratação em ambiente naturalmente ventilado. A desidratação parcial em uma sala ventilada naturalmente resultou em mudanças nas características físico-químicas das uvas Merlot, incluindo uma diminuição na aw (6\%), $\mathrm{pH}(4 \%)$ e dureza da baga $(58 \%)$, juntamente com um aumento no teor de sólidos solúveis totais (15\%). A presença de Pestalotiopsis clavispora, Neopestalotiopsis clavispora, Colletotrichum siamense e Alternaria porri foram favorecidas durante o processo de desidratação, enquanto uma diminuição na ocorrência de Aspergillus niger e Phanerochaete sp. foi verificada. Isolados de A. niger não mostraram potencial para produzir ocratoxina A. Essa toxina também não foi encontrada nas amostras de uva ao longo da desidratação.
\end{abstract}

Palavras-chave: ocratoxinas; micobiota; propriedades enológicas, Aspergillus niger.

\section{Introdução}

Utilizada em várias regiões do mundo para a produção de vinhos especiais, a desidratação de uvas tem como objetivo agregar valor aos produtos enológicos. A desidratação em ambientes cobertos (câmaras ou salas) pode ser realizada independentemente das condições climáticas, além dos benefícios de proteger as uvas dos danos de pássaros, insetos e da poluição ambiental (KHIARI; ZEMNI; MIHOUBI, 2019; MENCARELLI; BELLINCONTRO, 2018). Quando a desidratação é realizada em uma sala com ventilação natural, as janelas permanecem abertas para a circulação de ar e o procedimento ocorre em condições não controladas, sendo vantajoso para ser implementado sem custos adicionais relacionados a uma infraestrutura específica (MENCARELLI; BELLINCONTRO, 2018).

A ocorrência de fungos filamentosos nas uvas é uma das principais preocupações relacionadas à desidratação, uma vez que tais microrganismos podem produzir metabólitos secundários tóxicos denominados micotoxinas (LORENZINI et al., 2018). Reconhecida como a principal micotoxina detectada em derivados de uvas, a ocratoxina A (OTA) é principalmente associada a efeitos nefrotóxicos, sendo classificada pela Agência Internacional para Pesquisa sobre o Câncer (IARC) como possível carcinogênico para humanos (IARC, 1993). A OTA é produzida por algumas espécies de Aspergillus, principalmente por Aspergillus section Nigri.
Este estudo teve como objetivo avaliar as características físico-químicas, incidência de fungos e ocratoxina $A$ em uvas Merlot submetidas à desidratação em ambiente naturalmente ventilado.

\section{Material e Métodos}

Uvas da cultivar Merlot (safra fevereiro/2018) foram colhidas manualmente a partir de um vinhedo localizado no município de Flores da Cunha-RS, Brasil. Após a colheita, as uvas foram submetidas ao processo de desidratação parcial em ambiente coberto e naturalmente ventilado durante 21 dias (Figura 1). Amostras de uvas foram colhidas antes (T0) e após 7, 14 e 21 dias de desidratação (T7, T14 e T21, respectivamente) para avaliação das características físico-químicas, análises micológicas e determinação de ocratoxinas.

Um analisador de textura (TA.XT Plus, Stable Micro System) equipado com uma plataforma HDP / 90 e uma célula de carga de $5 \mathrm{~kg}$ foi utilizado para avaliar dureza e espessura da casca das uvas, de acordo com o método descrito por Segade et al. (2011). A determinação da atividade de água (Aw) foi realizada em medidor Aqualab (3TE-Decagon, Pullman). As uvas ainda foram avaliadas quanto ao teor de sólidos solúveis totais (TSST), em refratômetro (25BRIX/ATC, Megabrix), e pH (medidor modelo HI2221, Hanna Instruments).

\footnotetext{
*Instituto de Ciência e Tecnologia de Alimentos, Universidade Federal do Rio Grande do Sul (UFRGS), Avenida Bento Gonçalves n 9500, Porto Alegre, RS, Brazil. 91501-970. Email: juliane.welke@ufrgs.br

${ }^{* *}$ Centro de Biotecnologia, Programa de Pós-Graduação em Biologia Celular e Molecular, Universidade Federal do Rio Grande do Sul (UFRGS), Av. Bento Gonçalves, $n^{\circ}$ 9500, Porto Alegre, Brazil. 91501-970.
} 


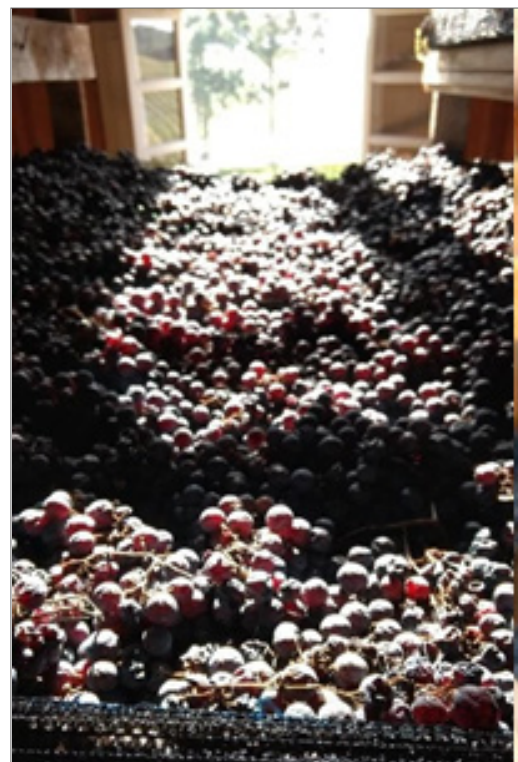

A

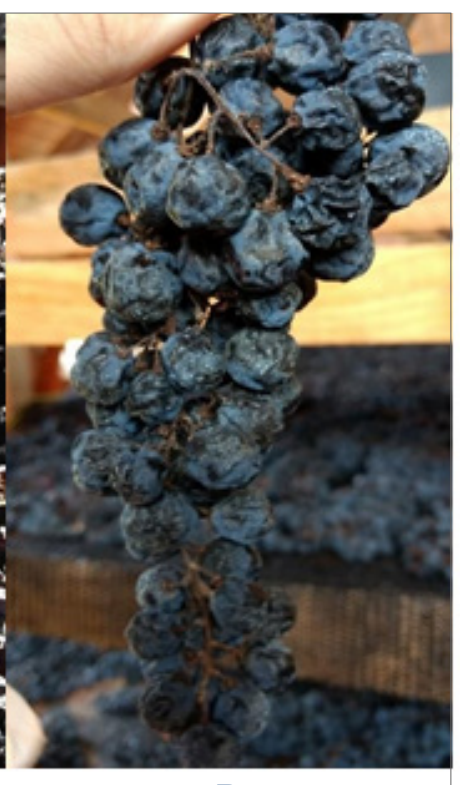

B
Figura 1. Processo de desidratação natural das uvas Merlot. (A) Imagem do local coberto e arejado onde as uvas foram desidratadas e (B) cacho de uva após 21 dias de desidratação.

Para as análises micológicas, as uvas foram desinfetadas superficialmente por imersão em solução de hipoclorito de sódio a $0,4 \%$ durante 1 minuto. Cem bagas de cada amostra foram plaqueadas em meio Dicloran Rosa de Bengala Cloranfenicol (DRBC) e incubadas durante 7 dias a $25^{\circ} \mathrm{C}$. As colônias fúngicas obtidas foram isoladas em Agar Extrato de Malte (MEA) e Agar Extrato de Levedura Czapek (CYA) e identificadas utilizando critérios morfológicos (PITT; HOCKING, 2009) e análise molecular através do sequenciamento de região ITS (Internal Transcribed Spacer) do DNA ribossomal (LOPES et al. 2011).

As espécies identificadas foram avaliadas quanto ao seu potencial toxigênico. Após cultivo dos fungos em meio CYA durante 7 dias a $25^{\circ} \mathrm{C}$, a extração de micotoxinas foi realizada pela técnica do Ágar Plug, seguido de detecção por cromatografia líquida acoplada a espectrometria de massas do tipo quadrupolo tempo de voo (LC-QToF-MS). Amostras de uvas desidratadas também foram avaliadas por LC-QToF-MS quanto à presença de ocratoxina $\mathrm{A}$.
Todos os experimentos foram realizados em triplicata. As análises estatísticas foram realizadas no software XLSTAT2017 (Addinsoft, New York, USA).

\section{Resultados e discussão}

Conforme previsto, mudanças significativas nas características físico-químicas das uvas ocorreram durante o processo de desidratação parcial (Tabela 1). 0 aumento de $15 \%$ nos níveis de TSST das bagas ao final da desidratação demonstrou que tal processo é favorável para a obtenção de uvas destinadas à produção de vinhos especiais. Uvas com ${ }^{\circ}$ Brix acima de 23 promovem um maior teor de álcool e / ou maiores níveis de açúcar residual em vinhos especiais (OIV, 2010). Por outro lado, ocorreu uma redução significativa na dureza das bagas, bem como na Aw e pH (58, 6 e 4\%, respectivamente), durante a desidratação. Tais mudanças estão atribuídas à evaporação de água, uma vez que tal fenômeno influencia na pressão de turgor das bagas e na concentração de açúcares e ácido orgânico.

A Figura 1 apresenta a ocorrência de fungos durante a desidratação parcial de uvas Merlot. Ao final do processo, foi possível verificar um aumento de $75 \%$ no número de bagas onde houve crescimento fúngico (Figura 2A). Tal fato pode ser justificado pela redução na dureza da baga à medida que o tempo de desidratação avançada. Estudos apontaram a dureza como um fator chave para a colonização fúngica das uvas (DACHERY et al. 2019; VERAS et al., 2021). Os fungos isolados foram identificados como Pestalotiopsis clavispora, Neopestalotiopsis clavispora, Colletotrichum siamense, Alternaria porri, Phanerochaete sp. e Aspergillus niger. A Figura 2B mostra o percentual de fungos isolados das uvas em cada período da desidratação, podendo observar uma redução no número de isolados de $A$. niger. Tal resultado é considerado relevante, uma vez que este fungo é comumente encontrado em uvas e potencialmente descrito como produtor de ocratoxina A e fumonisina B2 (FERRANTI et al., 2018; PANTELIDES et al., 2017). Curiosamente, espécies de Aspergillus carbonarius não foram isoladas das bagas. A ocorrência de $A$. carbonarius em vinhedos ao redor do mundo é menos comum do que $A$. niger (FERRANTI et al., 2018; PANTELIDES et al., 2017; GARMENDIA; VERO, 2016; CHIOTTA et al., 2013).

Tabela 1: Características físico-químicas das uvas Merlot durante o processo de desidratação em ambiente com ventilação natural.

\begin{tabular}{ccccc}
\hline \multirow{2}{*}{ Parâmetro } & \multicolumn{4}{c}{ Tempo de desidratação das uvas (dias) } \\
\cline { 2 - 5 } & T0 & T7 & T14 & T21 \\
\hline TSST $^{\circ}\left({ }^{\circ}\right.$ Brix $)$ & $20,7 \pm 0,1 \mathrm{a}$ & $21,2 \pm 0,3 \mathrm{~b}$ & $22,4 \pm 0,1 \mathrm{c}$ & $23,9 \pm 0,2 \mathrm{~d}$ \\
Dureza das bagas $(\mathrm{N})$ & $2,51 \pm 0,05 \mathrm{a}$ & $1,61 \pm 0,02 \mathrm{~b}$ & $1,38 \pm 0,04 \mathrm{c}$ & $1,05 \pm 0,03 \mathrm{~d}$ \\
Espessura da casca $(\mathrm{mm})$ & $0,21 \pm 0,02 \mathrm{a}$ & $0,22 \pm 0,03 \mathrm{a}$ & $0,22 \pm 0,02 \mathrm{a}$ & $0,22 \pm 0,02 \mathrm{a}$ \\
$\mathrm{Aw}{ }^{\mathrm{b}}$ & $0,98 \pm 0,00 \mathrm{a}$ & $0,96 \pm 0,00 \mathrm{~b}$ & $0,95 \pm 0,00 \mathrm{c}$ & $0,92 \pm 0,00 \mathrm{~d}$ \\
$\mathrm{pH}$ & $4,25 \pm 0,00 \mathrm{a}$ & $4,21 \pm 0,01 \mathrm{~b}$ & $4,15 \pm 0,02 \mathrm{c}$ & $4,07 \pm 0,00 \mathrm{~d}$ \\
\hline
\end{tabular}

a TSST: teor de sólidos solúveis totais; ${ }^{b}$ Aw: atividade de água; Letras diferentes na mesma linha indicam diferença significativa de acordo com ANOVA seguida do teste de Tukey $(p<0,05)$. 


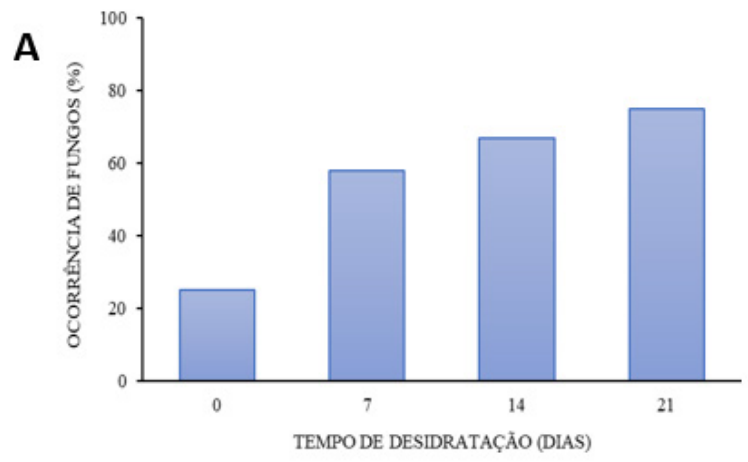

B

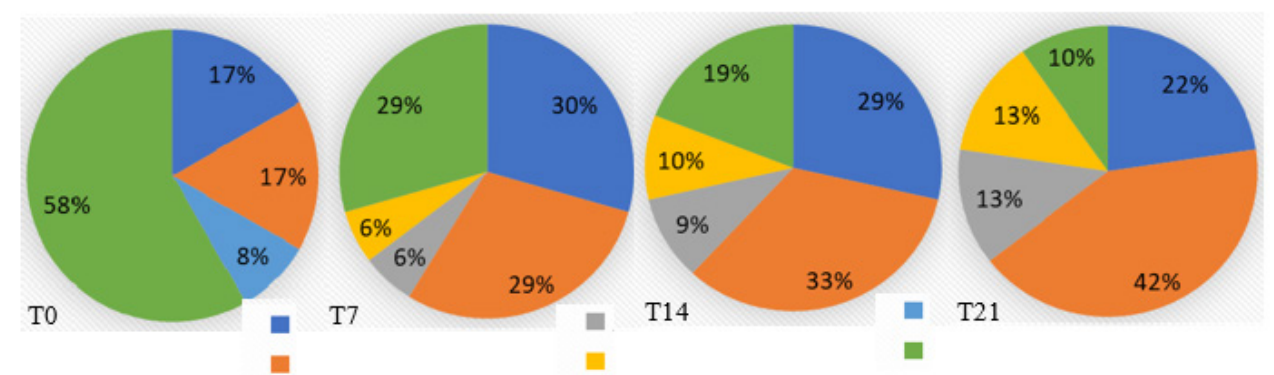

Figura 2: Porcentagem de bagas na qual foi verificada a ocorrência de fungos durante o processo de desidratação das uvas em ambientes ventilados naturalmente (A). Porcentagem da ocorrência de fungos provenientes dessas uvas $(B)$.

Os isolados de $A$. niger não apresentaram potencial para produzir ocratoxina A. Da mesma forma, esta micotoxina não foi detectada nas amostras de uvas, antes e durante a desidratação.

\section{Conclusões}

Este estudo demonstrou que a desidratação parcial de uvas afeta positivamente características físico-químicas das uvas

\section{Referências}

CHIOTTA, M. L.; PONSONE, M. L.; SOSA, D. M.; COMBINA, M.; CHULZE, S. N. Biodiversity of Aspergillus section Nigri populations in Argentinian vineyards and ochratoxin $A$ contamination. Food Microbiology, v. 36, n. 2, p. 182-190, 2013.

DACHERY, B.; HERNANDES, K. C.; VERAS, F. F.; SCHMIDT, L.; AUGUSTI, P. R.; MANFROI, V., ZINI, C. A.; WELKE, J. E. Effect of Aspergillus carbonarius on ochratoxin a levels, volatile profile and antioxidant activity of the grapes and respective wines. Food Research International, v. 126(September), 108687, 2019.

FERRANTI, L. DE S.; FUNGARO, M. H. P.; MASSI, F. P.; SILVA, J. J. DA; PENHA, R. E. S.; FRISVAD, J. C.; TANIWAKI, M. H.; IAMANAKA, B. T. Diversity of Aspergillus section Nigri on the surface of Vitis labrusca and its hybrid grapes. International Journal of Food Microbiology, v. 268(January), p. 53-60, 2018.

GARMENDIA, G.; VERO S. Occurrence and biodiversity of Aspergillus section Nigri on 'Tannat' grapes in Uruguay. International Journal of Food Microbiology, v. 216, p. 31-39, 2016.
Merlot. Apesar do processo promover a ocorrência de fungos, a redução gradativa na incidência de Aspergillus niger foi verificada ao longo do período de desidratação, e os isolados não se mostraram produtores de ocratoxina A. Esta micotoxina também não foi encontrada nas uvas avaliadas ao longo da desidratação. Desta forma, a desidratação parcial das uvas Merlot em sala ventilada naturalmente pode ser considerada uma estratégia promissora para a diversificação de produtos enológicos.

IARC. International Agency for Research on Cancer. Some naturally occurring substances: food items and constituents, heterocyclic aromatic amines and mycotoxins. IARC monographs on the evaluation of carcinogenic risks to humans, v. 56, p. 489-521, 1993.

KHIARI, R.; ZEMNI, H.; MIHOUBI, D. Raisin processing: physicochemical, nutritional and microbiological quality characteristics as affected by drying process. Food Reviews International, v. 35, n. 3, p. 246-298, 2019.

LOPES, F. C.; SILVA, L. A. D. E.; TICHOTA, D. M.; DAROIT, D. J.; VELHO, R. V.; PEREIRA, J. Q.; CORREAA, A. P. F.; BRANDELLI, A. Production of proteolytic enzymes by a keratin-degrading Aspergillus niger. Enzyme Research, 2011(1).

LORENZINI, M.; SIMONATO, B.; FAVATI, F.; BERNARDI, P.; SBARBATI, A.; ZAPPAROLI, G. Filamentous fungi associated with natural infection of noble rot on withered grapes. International Journal of Food Microbiology, v. 272, p. 83-86, 2018.

MENCARELLI, F.; BELLINCONTRO, A. Recent advances in postharvest technology of the wine grape to improve the wine aroma. Journal of the Science of Food and Agriculture, September 2018. 
OIV. (2010). Organization Internationale de la Vigne et du Vin. Resolution OIV/ECO 287/2010. http://www.oiv.int/public/ medias/1862/oiv-eco-287-2010-en.pdf.

PANTELIDES, I. S.; ARISTEIDOU, E.; LAZARI, M.; TSOLAKIDOU, M. D.; TSALTAS, D.; CHRISTOFIDOU, M.; KAFOURIS, D.; CHRISTOU, E.; IOANNOU, N. Biodiversity and ochratoxin A profile of Aspergillus section Nigri populations isolated from wine grapes in Cyprus vineyards. Food Microbiology, v. 67, p. 106-115, 2017.

PITT, J. I.; HOCKING, A. D. Fungi and Food Spoilage. 3 ed., New York: Springer Science 2009.
SEGADE, S. R.; GIACOSA, S.; GERBI, V.; ROLLE, L. Berry skin thickness as main texture parameter to predict anthocyanin extractability in winegrapes. LWT - Food Science and Technology, v. 44, n. 2, p. 392-398, 2011.

VERAS, F. F.; DACHERY, B.; MANFROI, V.; WELKE, J. E. Aspergillus carbonarius colonization and ochratoxin $A$ accumulation in Vitis vinifera, Vitis labrusca and hybrid grapes research of the most promising alternatives for organic viticulture. Journal of the Science of Food and Agriculture, v. 141, n. 1101145, 2021. 